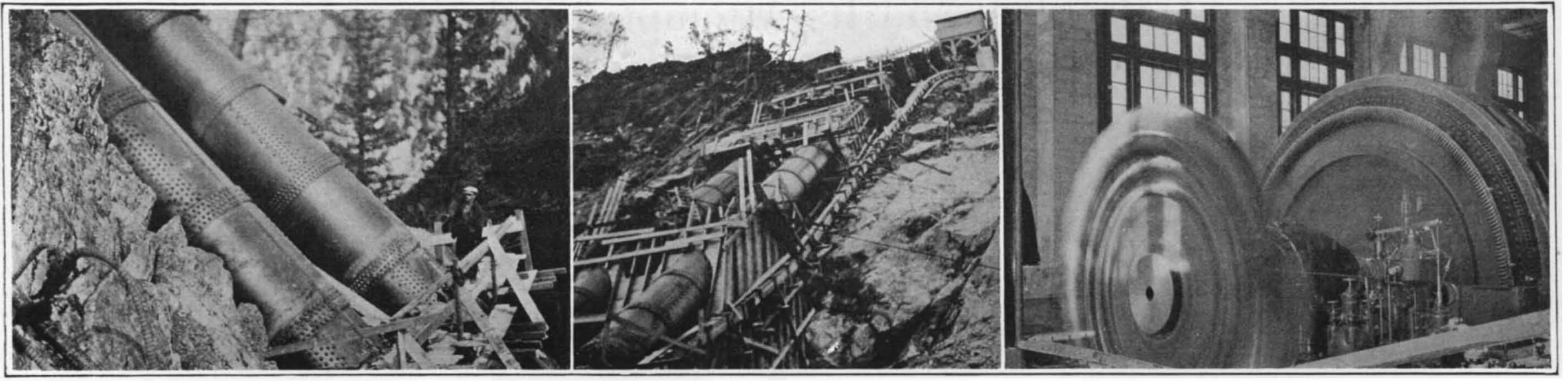

Left: A detail of the penstock on a grade of almost 100 per cent. Center: Anchoring the penstocks. Right: The big turbines and generators in actual operation

Views along the line of the Caribou power development

\section{The Caribou Power Plant}

By C. W. Geiger

THERE are many unusual features in connection with the new Caribou power plant recently placed in operation in California. Aluminum cables, nearly one inch in diameter, transmit the power generated at this plant over double-steel-tower transmission lines 186 miles to the San Francisco Bay distributing area. The voltage is 165,000 , the greatest voltage that is now carried on any transmission system in the world. Lake Almanor, from which the Caribou plant will draw a part of its waters, is the largest artificial power reservoir in the world. The submarine cables that deliver this power to San Francisco from across the bay, are the longest submarine cables of this voltage in the world.

The power development area of which the Caribou plant is a unit, begins in Lake Almanor, the source of the Feather River, and ends 75 miles distant, a drop in altitude of more than 4000 feet. The whole project in a nutshell consists in using the waters of the river over and over again during this drop (seven times) for the generation of hydro-electric power, and finally distributing them for irrigation when they have reached the Sacramento Valley levels.

Through the power thus developed there is now furnished more than 300,000 hydro-electric horsepower for California agriculture business and industry, including mines, factories, gold dredges, railroads, commercial and domestic lighting and coking and heating. Practically all of this service has been connected within ten years, and probably within the next fifteen years the Feather River development will reach 640,000 horsepower.

Because the Caribou power project was undertaken on the very heels of the cessation of World War hostilities, Central California is saved, this summer, the losses suffered from the power shortage of 1918, 1919, and 1920. Of even larger importance, this great area, with its rapidly increasing population, may go forward confidently in the development of its resources, knowing that, as the need arises, power and more power may and will flow to it from the perpetual reservoirs of the mountains. An interesting sidelight is found in the circumstance that where the Big Bend power house-the largest hydro-electric power plant west of the Mississippi-now stands, the waters of the Feather River were first diverted so that the sands of the river bed might be washed free of their golden weight. The very tunnel used for this purpose eventually became the power-house diversion tunnel. To feed the new Caribou power plant with water was in itself an engineering undertaking of magnitude. Tunnel No. 1, 11,200 feet long and with a capacity of 800 cubic feet of water per second, was built to carry the waters of Lake Almanor regulated by two sevenfoot electrically controlled gates, into Butt Valley, down which they course to Tunnel No. 2, 9200 feet long and with a capacity of 1400 cubic feet of water per second, which leads them to the pressure tunnel. At the bottom of the pressure tunnel, a horizontal tunnel 550 feet long, carries at the present time two sixty-inch steel penstocks which are attached to the pressure tunnel and made water tight by means of a large concrete plug. There is space in the horizonta tunnel for a third pipe of similar dimensions. The pipe lines emerge from the horizontal tunnel and are anchored on the surface of the hillside a distance of 547 feet to a point where they drop vertically into another tunnel known as the "uprise," which is about 550 feet deep. About half way down the "uprise" the sixty-inch pipes, by means of large $\mathrm{Y}$-connections, branch into four forty-two-inch pipes. A tunnel run- ning horizontally from the bottom of the "uprise" carries the pipe lines about 500 feet to the surface of the mountainside immediately back of the powe house. From this point the pipe lines are laid on concrete anchors to four hydraulically operated gate valves which are installed against the rear wall of the power house. From these valves the pipe line lead into the powe the water wheels. Space has been left in the "uprise" and horizontal tunnels for two more 42 -inch pipe lines. The two 30,000-horsepower units installed at present consist of two overhung impulse wheels, each with 21 buckets, operating under a head of 1008 feet, with a speed of 171 revolutions per minute. Each of the buckets of these wheels weighs 1000 pounds. Th diameter of the jet which strikes them is eleven inches. These wheels and generator constitute a unit. Each unit weighs 290 tons. The revolving element of each unit weighs 170 tons.

\section{The Soap-Nut Tree-A Last Chance}

UR old friend, E. Moulie, who used to be in Florida, but who is now established in San Gabriel, Cal., asks us to assist him in what he believes will be his last distribution of the seed of his beloved soap-nut tree. This tree, Sapindus Muskorossi, to give it its botanical name is some fifty feet tall when fully developed, and quite ornamental. Its timber resembles orange wood. It bears from the age of six years, the average crop being about 200 pounds of nuts per tree. These nuts are altogether extraordinary. It is the shell of the nut. that gives the tree its name; this shell is so rich in saponacenus material that the in the tree, can be used with excellent effect to wash the hands. This saponine of

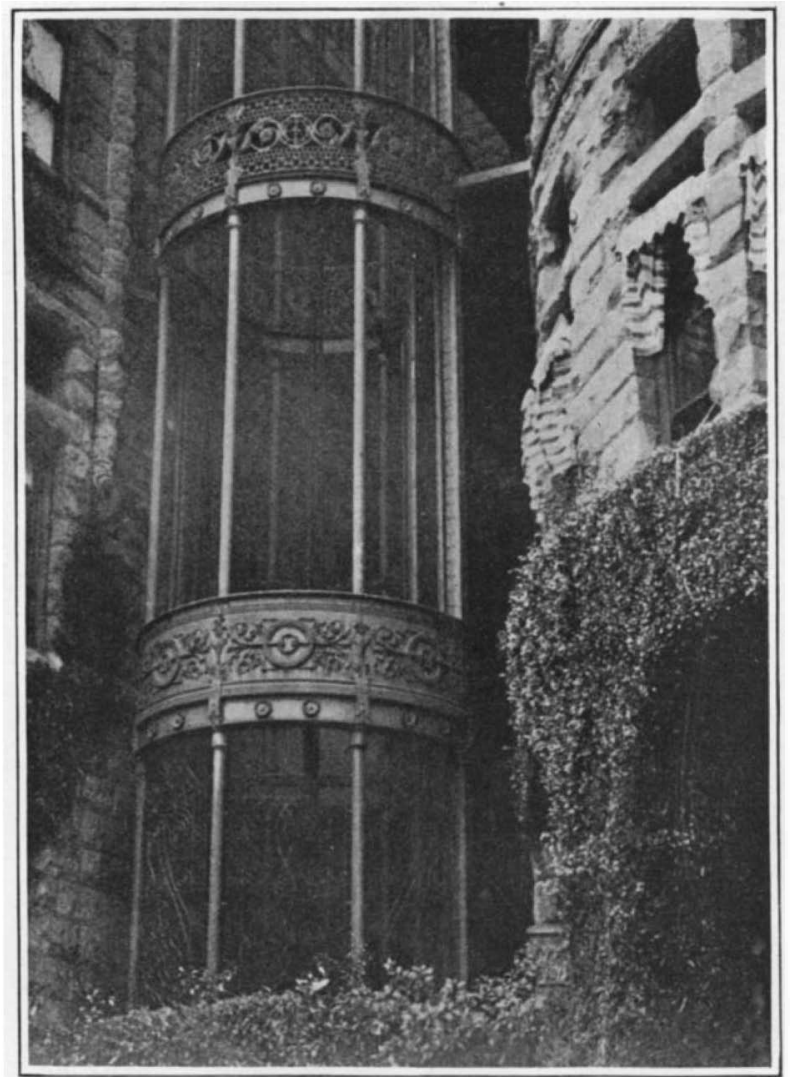

The out-of-doors elevator that was added to two Los Angeles buildings the hull washes everything from a lace handkerchief to a horse blanket, and is highly beneficial to the human skin as well as to the scalp. Inside is found an edible kernel, extremely rich in fats and high in food value.

Mr. Moulie has spent a good part of his long life (he is in his eighty-first year) in the effort to bring the soap-nut tree into more general cultivation in all places that are suited to it. On several occasions, after he has succeeded in accumulating from his own planta tions a supply of the nuts sufficient for the purpose he has conducted free distribution of the seed, with great success.

The soap-nut tree will not prosper in regions where the thermometer may be expected to drop below ten degrees, Fahrenheit and $\mathrm{Mr}$ Moulie will not send seeds to such localities. With this exception he is eager to have applications for the seed from any part of the world. The last time he distributed the seed he had so many requests that the labor and the expense of filling them nearly swamped him. He therefore insists that all applications addressed stamped envelope, plus ten cents to cover clerical work, etc. In return each applicant will receive ten tested soap-nut seeds, which will be sufficient nucleus for an extensive orchard. Mr. Moulie suggest that applicants from foreign countries send the ten cents in international postage coupons If United States stamps are not obtainable.

The seed will germinate sooner if planted in a hot bed, in a box or pot. The seeds should be planted 11 inches deep and the soil about it kept moderately moist When the seedling is about 18 inches tall it can be planted at the point in the open where it is desired to have the tree. It must be placed at.least 25 feet from any other large tree and the soil again kept moderately moist until the roots are well settled and the tree has started a healthy growth.

It is to be emphasized that Mr. Moulie's abject in asking us to make this announcement is to spread a widely as possible the cultivation of the tree over which he is so enthusiastic His distribution of 1918 was marked by numerous requests for the nuts in such quantities that it was plainly the intention of the applicants to use them for soap or for food-one lady actually asked for instructions as to their preparation for the table. Mr. Moulie is giving away seeds, not food; and he is giving them in such a way as to give them the maximum circulation. He will not undertake to acknowledge any letters that do not meet his conditions. In particular, do not ask for his nuts by the pound or the bushel; the supply is not unlimited, though $\mathrm{Mr}$. Moulie believes it is large enough to insure ten of the tested seeds to everybody who wants them. But from the figure which he names in his letter, if you are the 6001st applicant you may not get any seeds.

\section{How the Elevator Was Added}

THE solution of the elevator problem for two public 1 buildings in Los Angeles, two buildings that were built side by side, was an out-of-doors elevator. It was put up at the same time that the passageways from one building to the other were installed. This type of "open-air" car is possible owing to the lack of inclement weather and makes it possible for both buildings to be served by one system. At each landing there is a door into each building, and the elevator car is fitted with a door at each side. In addition to its practicability this style of system enables passengers to view the city, as the buildings are on the summit of a high hill.-By C. A. Goddard. 